\title{
Knowledge and Awareness of Caregivers about Diabetic Ketoacidosis among Type-1 Diabetic Children and Their Action and Response in Riyadh City
}

\author{
Abdulaziz Fahad Al Kaabba1*, Bandar Saleh Alzuair', Yara Faisal AlHarbi2, \\ Juhainah Abdullah Alshehri'2, Lujain Habeeb Allowaihiq², Maha Hamoud Alrashid², \\ Reema Awad Alkhatabi²
}

${ }^{1}$ Department of Family Medicine, College of Medicine, Imam Mohammad Ibn Saud Islamic University, Riyadh, Saudi Arabia ${ }^{2}$ College of Medicine, Imam Mohammad Ibn Saud Islamic University, Riyadh, Saudi Arabia

Email: *afkaabba@gmail.com

How to cite this paper: $\mathrm{Al}$ Kaabba, A.F., Alzuair, B.S., AlHarbi, Y.F., Alshehri, J.A., Allowaihiq, L.H., Alrashid, M.H. and Alkhatabi, R.A. (2021) Knowledge and Awareness of Caregivers about Diabetic Ketoacidosis among Type-1 Diabetic Children and Their Action and Response in Riyadh City. Open Journal of Endocrine and Metabolic Diseases, 11, 119-128.

https://doi.org/10.4236/ojemd.2021.115009

Received: February 23, 2021

Accepted: May 14, 2021

Published: May 17, 2021

Copyright $\odot 2021$ by author(s) and Scientific Research Publishing Inc. This work is licensed under the Creative Commons Attribution International License (CC BY 4.0).

http://creativecommons.org/licenses/by/4.0/

\section{cc) (i) Open Access}

\begin{abstract}
Objectives: Diabetic ketoacidosis (DKA) is a life-threatening metabolic disorder in which its complications can be avoidable. The purpose of this study is to identify and measure the level of knowledge and awareness of caregivers about the symptoms of DKA in children in Riyadh city. Setting and Participants: This cross-sectional study design was conducted in Riyadh city in Saudi Arabia. A sample size of at least 412 was required. The total number of respondents that were included in the analysis was 414 . The method of collection of data done by data collectors. Results: Two hundred and sixty-eight (64.7\%) of the participants reported that they know about DKA, yet it was still a concerning figure since $35.3 \%$ did not know about it, which necessitating diabetes self-management education at national levels in Saudi Arabia. Conclusion: This study showed that the majority of type-1 diabetic caregivers had knowledge and awareness regarding DKA in Riyadh, Saudi Arabia. Further studies would assess more factors to enhance the level of knowledge and awareness, and increase the effectiveness toward the right action and response regarding DKA.
\end{abstract}

\section{Keywords}

Diabetes Mellitus, DKA, Children, Caregivers, Emergency 


\section{Introduction}

Diabetic ketoacidosis (DKA) is an acute, serious, life-threatening complication of hyperglycemia, ketoacidosis, and ketonuria. It occurs when absolute or relative insulin deficiency prevents the ability of glucose to enter cells for using it as a metabolic fuel. As a result, the liver rapidly breaks down fat into ketones for use as a fuel source. The overproduction of ketones occurs, causing them to build up in the blood and urine and causing the blood to be acidic. DKA occurs primarily in type 1 diabetes patients, although it is not unusual in some type 2 diabetes patients. The insidious rise in polydipsia and polyuria are the most prominent early symptoms of DKA. Besides, other symptoms such as Malaise, generalized weakness, fatiguability, nausea and vomiting, diffuse abdominal pain and decreased appetite are also seen [1].

Patients and their families have been the object of self-treatment and the administrators of their care. The health care team were the guides who set the stage, efforts when the targets were not reached, rather than being the only diabetes health care team to initiate treatment, patients and parents were encouraged to evaluate their data, recognize patterns, resolve diet and activity issues, and do so based on real blood glucose results [2].

Mothers with more knowledge about diabetes and better education maintained better glycemic control of their children, irrespective of their socio-economic status, and to enhance glycemic control and minimize acute and chronic complications of diabetes in children, knowledge and education of mothers be important [3].

The most common emergency case when having a patient diagnosed with diabetes mellitus is Diabetic ketoacidosis (DKA). Surprisingly, it's more often when we see these patients suffering from DKA type 1 diabetes patients. However, type 2 diabetes patients are never spared from the susceptibility of suffering from this unfortunate emergency. Otherwise, it was noticeable that type $2 \mathrm{DM}$ patients are having a DKA were under the effect of certain situations such as post-operation, trauma or accident, or infectious diseases [4] [5].

DKA is reported to be responsible for more than 100,000 hospital admissions per year in the US and accounts for $4 \%$ - $9 \%$ of all hospital discharge summaries among patients with diabetes. Alhowaish (2013) has estimated more than 500\% acceleration in the expenses incurred for healthcare and treatment of diabetes since 2000 and costed the healthcare budget of Saudi Arabia roughly 25 billion used exclusively for the management of diabetes [6].

Diabetic ketoacidosis diagnosis is basically under few conditions, first of all, we need the patient's plasma glucose concentration to be above $250 \mathrm{mg}$ per $\mathrm{dL}$ (usually elevated above this number), and the bicarbonate level to be or less than $18 \mathrm{mEq}$ per $\mathrm{L}$, and the $\mathrm{pH}$ level is 7.30 or less. The main course of treatment for DKA is intravenous insulin and fluid replacement therapy, and obviously with precise checkup and monitoring of the potassium levels. To reach the full level of treatment, it is required to educate patients to prevent the recurrence of such 
a case [7].

For example, a study by Alwan et al. (2017) that studied the awareness about diabetes mellitus among attendees of primary health care centers, Makkah, Saudi Arabia has reported that the main sources for information about diabetes were mass media (57.4\%), health sector (29.9\%) and educational sector (10.6\%) and concluded a satisfactory level of knowledge about regarding risk factors, symptoms, and risks of diabetes but not aware of the diabetes associated secondary complications [8].

Moreover, Illiteracy and low socioeconomic status were significantly associated with poor knowledge and practice of diabetic foot care [9], and that the level of education is the most significant predictor of knowledge regarding risk factors, complications and the prevention of diabetes [10].

Overall, to help in bridging the gap in the literature about the knowledge of caregivers in Saudi Arabia, this study aims to identify and measure the level of knowledge and awareness of caregivers about the symptoms of DKA in children in Riyadh city.

\section{Methods}

Study Subjects. This study used a descriptive cross-sectional questionnairebased study design. It was conducted in Riyadh city in Saudi Arabia, from August through November 2020. Four hundred and fourteen persons were randomly selected populations of diabetic pediatric patients and their caregivers were asked to take part in an online-based survey. The inclusion criteria included being a caregiver for a diabetic child who resides in Riyadh during the study period. All participants received an online webpage with an explanation of the study purpose and were requested to provide informed consent before the online questionnaire being proceeded. The participants were encouraged to complete the questionnaire voluntarily within the time interval of the study and at their convenience. Moreover, the participants were given the chance to seek the help of a person of their choice to help them fill the form if they are unable to read or answer the form.

Sample Size. According to the Saudi Arabia General Authority for Statistics, there were 2,470,683 Saudi children aged $\leq 19$ years living in Riyadh in 2020 . Based on an acceptable error margin equivalent to $5 \%$ with a confidence interval of $95 \%$, a sample size of at least 412 was required. The dataset included 431 participants. We excluded participants who were taking care of diabetic patients aged above 16, and if there were refusing, did not know the responses to any of the variables of interest, or missing responses. The final sample size after exclusion was 414 .

Data Collection Tool. The questionnaire was adapted with the permission of Othman et al. and translated into Arabic. The translation process of the questionnaire included a cross-cultural validation, and a review by the translation committee of our institute. Prevention of responses repetition was made through 
the linking of every survey response with an internet protocol. The Medical College Institutional Review Board, Al-Imam Muhammad Ibn Saud Islamic University, Riyadh, Saudi Arabia has approved this study protocol.

Questionnaire. This study employed a self-administrated questionnaire, which included 30 items on related knowledge and awareness of caregivers about DKA among their type 1 diabetic children and their action and response. If the participant is unable to answer the questionnaire due to literacy issues, the participants were given the chance to fill in the questionnaire with the help of another person of their choice. The questionnaire was presented in two major sections: 14 questions on general demographic characteristics, and 16 questions on DKA knowledge, attitudes, actions and responses.

Data Analysis. The data were collected from an online platform, tabulated by using Microsoft Excel 2016 and analyzed using SPSS software version 26. The categorical variables were presented as percentages and frequencies. Both logistic regression tests and univariate chi-square analysis were conducted to determine the associations between the knowledge and attitude and the participants' general characteristics, also their attitude and response to the accepted level of knowledge, to obtain odds ratios for adjusted and unadjusted models. A P-value of $<0.05$ was considered statistically significant.

\section{Results}

\section{Demographic features of the respondents concerning their diabetic status}

Four hundred and fourteen responded exceeding the estimated sample size of 412. Most of the participants were in the age range of 30 - 49 years old (244; $59 \%)$ and non-diabetic $(323 ; 78.0 \%)$. Half of the participants $(263 ; 63.5 \%)$ are university graduates, and $(207 ; 50 \%)$ of the participants are employed (Table 1$)$.

The diabetic status of the participants was highest among participants who are less than 20 years $(25 ; 6.0 \%)$, with university degrees $(56 ; 13.5 \%)$, and among unemployed $(57 ; 13.8 \%)$. All of the non-diabetics were educated $323(10 \%)$ (P-value < 0.001).

Knowledge about DKA symptoms, signs, complications and prevention

Two hundred and sixty-eight (64.7\%) of the participants reported that they know about DKA.

Table 2 summarizes the awareness and knowledge of the caregivers regarding the symptoms and signs of DKA. The most known symptom of DKA was the characteristic smell of breathing $(290 ; 70.0 \%)$ while the least known was the skin coldness (122; 29.5\%).

As for the seriousness of DKA, 326 (78.7\%) of the participants considered it as a very life-threatening case for the child, compared to 31 (7.5\%) who considered it a simple condition. While for the knowledge about complications of DKA, 262 (63.3\%) reported that they know about them. 285 (68.8\%) reported they knew it could lead to coma, while 255 (61.6\%) did not know that it could lead to brain swelling. 
Table 1. Demographic features of caregivers of diabetic children $(\mathrm{N}=414)$.

\begin{tabular}{|c|c|c|c|c|c|c|c|c|c|}
\hline \multirow{2}{*}{ Demographic feature } & \multirow{2}{*}{\multicolumn{2}{|c|}{ Not diabetic }} & \multirow{2}{*}{\multicolumn{2}{|c|}{ Diabetic }} & \multirow{2}{*}{\multicolumn{2}{|c|}{ Total }} & \multicolumn{3}{|c|}{ Statistical significance } \\
\hline & & & & & & & $\mathrm{X}^{2}$ & $\mathrm{df}$ & P-value \\
\hline $20-29$ & 45 & $10.9 \%$ & 21 & $5.1 \%$ & 66 & $15.9 \%$ & \multirow{5}{*}{42.38} & \multirow{5}{*}{4} & \multirow{5}{*}{0.000} \\
\hline $30-39$ & 102 & $24.6 \%$ & 10 & $2.4 \%$ & 112 & $27.1 \%$ & & & \\
\hline $40-49$ & 112 & $27.1 \%$ & 20 & $4.8 \%$ & 132 & $31.9 \%$ & & & \\
\hline 50 or more & 39 & $9.4 \%$ & 15 & $3.6 \%$ & 54 & $13.0 \%$ & & & \\
\hline Less than 20 & 25 & $6.0 \%$ & 25 & $6.0 \%$ & 50 & $12.1 \%$ & & & \\
\hline \multicolumn{10}{|l|}{ Educational level } \\
\hline Illiterate & 0 & $0.0 \%$ & 3 & $0.7 \%$ & 3 & $0.7 \%$ & \multirow{6}{*}{26.04} & \multirow{6}{*}{5} & \multirow{6}{*}{0.000} \\
\hline Primary school & 2 & $0.5 \%$ & 4 & $1.0 \%$ & 6 & $1.4 \%$ & & & \\
\hline Intermediate-Elementary school & 16 & $3.9 \%$ & 5 & $1.2 \%$ & 21 & $5.1 \%$ & & & \\
\hline Secondary School & 70 & $16.9 \%$ & 23 & $5.6 \%$ & 93 & $22.5 \%$ & & & \\
\hline University & 207 & $50.0 \%$ & 56 & $13.5 \%$ & 263 & $63.5 \%$ & & & \\
\hline Postgraduate Studies & 28 & $6.8 \%$ & 0 & $0.0 \%$ & 28 & $6.8 \%$ & & & \\
\hline \multicolumn{10}{|l|}{ Employment status } \\
\hline Health-related & 21 & $5.1 \%$ & 10 & $2.4 \%$ & 31 & $7.5 \%$ & \multirow{3}{*}{11.48} & \multirow{3}{*}{2} & \multirow{3}{*}{0.003} \\
\hline Not health-related & 148 & $35.7 \%$ & 24 & $5.8 \%$ & 172 & $41.5 \%$ & & & \\
\hline Unemployed & 154 & $37.2 \%$ & 57 & $13.8 \%$ & 211 & $51.0 \%$ & & & \\
\hline
\end{tabular}

Table 2. Awareness and knowledge of the caregivers regards the sign and symptoms of DKA.

\begin{tabular}{|c|c|c|c|}
\hline \multicolumn{2}{|c|}{ What are the symptoms and signs of DKA? } & \multirow{2}{*}{$\begin{array}{c}\text { Frequency } \\
118\end{array}$} & \multirow{2}{*}{$\begin{array}{c}\text { Percentage } \\
28.5\end{array}$} \\
\hline & Don’t know & & \\
\hline \multirow[t]{3}{*}{ Colic } & No & 52 & 12.6 \\
\hline & Yes & 244 & 58.9 \\
\hline & Don’t know & 98 & 23.7 \\
\hline \multirow[t]{3}{*}{ Vomiting } & No & 42 & 10.1 \\
\hline & Yes & 274 & 66.2 \\
\hline & Don’t know & 199 & 48.1 \\
\hline \multirow[t]{3}{*}{ Skin coldness } & No & 93 & 22.5 \\
\hline & Yes & 122 & 29.5 \\
\hline & Don’t know & 143 & 34.5 \\
\hline \multirow[t]{3}{*}{ Disturbance of consciousness } & No & 51 & 12.3 \\
\hline & Yes & 220 & 53.1 \\
\hline & Don’t know & 119 & 28.7 \\
\hline \multirow[t]{3}{*}{ Body weakness } & No & 44 & 10.6 \\
\hline & Yes & 251 & 60.6 \\
\hline & Don't know & 86 & 20.8 \\
\hline \multirow[t]{2}{*}{ The characteristic smell of breathing } & No & 38 & 9.2 \\
\hline & Yes & 290 & 70.0 \\
\hline
\end{tabular}


Also, $262(63.3 \%)$ reported they know that DKA can lead to severe dehydration $368(88.9 \%)$ of the participants that DKA can be prevented by taking insulin as directed, while 366 (88.4\%) mentioned continuous blood glucose monitoring.

DKA, 285 (68.8\%) agree that DKA can be complicated leading to Coma.

\section{Discussion}

This research was conducted to assess caregivers' knowledge about pediatric type-1 diabetic in the Riyadh Region. Most of the participants were in the age range of $30-49$ years old $(244 ; 59 \%)$, which is consistent with the overall age distribution of the Saudi population, of whom those in the same age group represent $37 \%$ of the population as per the latest census in 2016 [9] [10]. Also, most of the caregivers were non-diabetic (323; 78.0\%), which seem to be consistent with the WHO's estimate of the prevalence of DM in KSA at 14.4\% [11]. However, there are recent studies that suggest a much higher prevalence of DM in the Saudi population at more than $30 \%$ [10] [12] [13]. Half of the participants (207; 50.0\%) were university graduates and employed, which is consistent with the national figures that estimate those who are currently studying at universities at more than two million and those employed at more than 3 million [14] [15] [16] [17] [18].

The diabetic status of the participants was highest among participants who are less than 20 years or more $(25 ; 6.0 \%)$, which can be explained by the focus of the study, i.e. pediatric diabetes. DM was also highest among the unemployed (57; $13.8 \%$ ), which may be seen as both a cause and a result. For example, Weinstein (2004), Naeem (2015), and Dagenais (2016) suggested that unemployment can be a result of DM due to disability and early mortality by disease [19] [20] [21], while others have suggested that it may contribute to the development of DM as a result of diminished healthy choices, lack of movement, and reduction in income [22] [23].

Most of the participants were unemployed and non-diabetic (154; 37.2\%), which could be attributed to the caregivers being mostly women (mothers) who were not working. Moreover, given that the focus of the study is type 1, which is not hereditary, it is unlikely to find as many diabetic mothers.

Interestingly, all of the non-diabetics were educated $323(10 \%)(\mathrm{P}$-value $=0.000)$. This finding is unlike Seiglie et al. (2020) who found that compared with no formal education; greater educational attainment was associated with an increased risk of diabetes across the 29 countries they included, after adjusting for BMI [23].

Regarding the awareness and knowledge of the caregivers regarding the symptoms, signs and complications of DKA, this study seems to reflect better results compared to previous studies, like that by Farran et al. (2020) who found that $38.67 \%$ of our participants have a poor awareness regarding DKA complications [15].

However, the percentages of those who reported DKA could lead to coma $(285 ; 68.8 \%)$ are comparable to the $59.3 \%$ they found in the same study. 
Although 46\% know about DKA and $78.7 \%$ know that it is a life-threatening case for a child who is good, yet it was still an alarming figure since $35 \%$ did not know about it and 7.5\% think it a simple case and that requires diabetes self-management education at national levels in Saudi Arabia. Also, 66\% agreed that sign of DKA is vomiting but less apparent symptoms were less known, $28 \%$ and $34 \%$ for colic pain and disturbance of consciousness, respectively is worrying because they may indicate an emergency indication of DKA.

Caregivers' knowledge about how to prevent the DKA was surprising since generally satisfactory at $\mathbf{8 8 . 9 \%}$ yet those who thought they should wait and continue to monitor the blood glucose level about $88.4 \%$. This requires diabetes educators to educate pediatric patients and the caregiver about "sick day management". Similar conclusions were reached by other authors who studied diabetes in Saudi Arabia and elsewhere [24] [25] [26] [27].

The patients with DKA are prone to dehydration since that hyperglycemia, fever, excessive glycosuria and ketonuria increase fluid losses which must be replaced immediately (fluids should also contain water with salt if there are ongoing losses of fluids such as vomiting or diarrhea. Additionally, in the presence of loss of appetite or decreased blood glucose below approximately $10 \mathrm{mmol} / \mathrm{L}$ (180 $\mathrm{mg} / \mathrm{dL}$ ), sugar-containing fluids should also be considered to avoid starvation ketosis).

Diabetes Educators must inform caregivers that during the illness never stop insulin, but must to do Self-monitoring of blood glucose and increase the dose if needed and if they do not improve and ketones become significantly positive, and then they must go to the emergency to prevent further complications of DKA. Since we notice that range $61 \%$ to $68 \%$ of the responded know the complication of DKA could be coma, swelling of the edema and severe dehydration.

\section{Limitations}

As would be expected with this kind of studies, there are a few limitations. These include that the study was done in only one region of the country and it used questionnaires as its main data collection method. This could have limited a more geographical variation and may have caused some participants who are not able to read some difficulties filling them. That said, it is worth noting that Riyadh is the home of almost one third of the Saudi population from various regions of the country. Also, the participants were given the choice to seek the help of a person of their choice, should they have difficulties in reading or filling the form. Another limitation was lack of testing of validity and reliability of the study, which may have increased the power and reliability of our findings.

\section{Conclusions}

Most caregivers in this study show knowledge and awareness regarding the signs and symptoms of DKA, however, they need further education since most of them have lack knowledge of sick day management and how it is critical. 
The main factors related to this positive reflection of knowledge and awareness were the level of education of the caregivers. These study findings suggest that it might be beneficial to educate caregivers of type- 1 diabetic patients and the patients themselves about DKA's self-management, using insulin, and monitoring of blood glucose to prevent complications. This study has potential limitations. Our study is a cross-sectional study. Therefore, difficulty in recalling is a possibility that could affect the validity of the results. Furthermore, we cannot generalize our result to the kingdom of Saudi Arabia, as this study concerns with the Riyadh region only.

\section{Conflicts of Interest}

The authors declare no conflicts of interest regarding the publication of this paper.

\section{References}

[1] Hamdy, O. (2021) Diabetic Ketoacidosis (DKA): Practice Essentials, Background, Pathophysiology.

[2] Brink, S.J. and chiarelli, F.G. (2004) Education and Multidiscipplinary Team Approch in Childhood Diabetes. Acta Biomedica Atenei Parmensis, 75, 7-21.

[3] Al-Odayani, A.N., Alsharqi, O.Z., Ahmad, A.M.K., et al. (2013) Children's Glycemic Control: Mother's Knowledge and Socioeconomic Status. Global Journal of Health Science, 5, 214-226. https://doi.org/10.5539/gjhs.v5n6p214

[4] Kitabchi, A.E., Umpierrez, G.E., Miles, J.M., et al. (2009) Hyperglycemic Crises in Adult Patients with Diabetes. Diabetes Care, 32, 1335-1343. https://doi.org/10.2337/dc09-9032

[5] Umpierrez, G.E., Jones, S., Smiley, D., et al. (2009) Insulin Analogs versus Human Insulin in the Treatment of Patients with Diabetic Ketoacidosis: A Randomized Controlled Trial. Diabetes Care, 32, 1164-1169. https://doi.org/10.2337/dc09-0169

[6] Alhowaish, A. (2013) Economic Costs of Diabetes in Saudi Arabia. Journal of Family \& Community Medicine, 20, 1-7. https://doi.org/10.4103/2230-8229.108174

[7] Trachtenbarg, D.E. (2005) Diabetic Ketoacidosis. American Family Physician, 71, 1705-1714. https://doi.org/10.1177/1755738017735779

[8] Alwan, Y.M.S., Alayed, I.S. and Albarakati, M.H. (2017) Assessing Awareness about Diabetes Mellitus among Attendees of Primary Health Care Centers, Makkah, Saudi Arabia. The Egyptian Journal of Hospital Medicine, 66, 57-65. https://doi.org/10.12816/0034634

[9] Desalu, O.O., Salawu, F.K., Jimoh, A.K., et al. (2011) Diabetic Foot Care: Self Reported Knowledge and Practice among Patients Attending Three Tertiary Hospital in Nigeria. Ghana Medical Journal, 45, 60-65. https://doi.org/10.4314/gmj.v45i2.68930

[10] Salem, A., Majed, A., Mahfooz Mustafa, M.A., et al. (2018) Knowledge, Attitude, and Practice Regarding Diabetes Mellitus among General Public and Diabetic Patients in Riyadh, Saudi Arabia. Asian Journal of Pharmaceutics, 12, S269.

[11] Abdulaziz Al Dawish, M., Alwin, R.A., Braham, R., et al. (2016) Diabetes Mellitus in Saudi Arabia: A Review of the Recent Literature. Current Diabetes Reviews, 12, 359 368. https://doi.org/10.2174/1573399811666150724095130 
[12] Al-Rubeaan, K. (2015) National Surveillance for Type 1, Type 2 Diabetes and Prediabetes among Children and Adolescents: A Population-Based Study (SAUDI-DM). Journal of Epidemiology and Community Health, 69, 1045-1051. https://doi.org/10.1136/jech-2015-205710

[13] Salti, N. (2020) Non-Communicable Diseases (NCD) in the Middle East and North Africa: What Macroeconomic Savings Can Be Expected from Achieving SDG Target 3.4? Acknowledgements.

[14] Al-Aboudi, I.S., Hassali, M.A. and Shafie, A.A. (2016) Knowledge, Attitudes, and Quality of Life of Type 2 Diabetes Patients in Riyadh, Saudi Arabia. Journal of Pharmacy and Bioallied Sciences, 8, 195-202. https://doi.org/10.4103/0975-7406.171683

[15] Farran, B., Bin, E.R., Aldarsouny, A., et al. (2020) Level of Awareness of Diabetic Ketoacidosis among Diabetes Mellitus Patients in Riyadh. Journal of Family Medicine and Primary Care, 9, 2676-2679. https://doi.org/10.4103/jfmpc.jfmpc_385_20

[16] Whitaker, S.M., Bowie, J.V., McCleary, R., et al. (2014) The Association between Educational Attainment and Diabetes among Men in the United States. American Journal of Men's Health, 8, 349-356. https://doi.org/10.1177/1557988313520034

[17] Elhadd, T.A., Al-Amoudi, A.A. and Alzahrani, A.S. (2007) Epidemiology, Clinical and Complications Profile of Diabetes in Saudi Arabia: A Review. Annals of Saudi Medicine, 27, 241-250. https://doi.org/10.5144/0256-4947.2007.241

[18] Agardh, E., Allebeck, P., Hallqvist, J., et al. (2011) Type 2 Diabetes Incidence and Socio-Economic Position: A Systematic Review and Meta-Analysis. International Journal of Epidemiology, 40, 804-818. https://doi.org/10.1093/ije/dyr029

[19] Weinstein, A.R., Sesso, H.D., Lee, I.M., et al. (2004) Relationship of Physical Activity vs Body Mass Index with Type 2 Diabetes in Women. JAMA, 292, 1188-1194. https://doi.org/10.1001/jama.292.10.1188

[20] Dagenais, G.R., Gerstein, H.C., Zhang, X., et al. (2016) Variations in Diabetes Prevalence in Low-, Middle-, and High-Income Countries: Results from the Prospective Urban and Rural Epidemiological Study. Diabetes Care, 39, 780-787. https://doi.org/10.2337/dc15-2338

[21] Naeem, Z. (2015) Burden of Diabetes Mellitus in Saudi Arabia. International Journal of Health Sciences (Qassim), 9, 5-6. https://doi.org/10.12816/0024690

[22] Sacerdote, C., Ricceri, F., Rolandsson, O., et al. (2012) Lower Educational Level Is a Predictor of Incident Type 2 Diabetes in European Countries: The EPIC-Interact Study. International Journal of Epidemiology, 41, 1162-1173. https://doi.org/10.1093/ije/dys091

[23] Seiglie, J.A., Marcus, M.-E., Ebert, C., et al. (2020) Diabetes Prevalence and Its Relationship with Education, Wealth, and BMI in 29 Low- and Middle-Income Countries. Diabetes Care, 43, 767-775. https://doi.org/10.2337/dc19-1782

[24] Howe, L.D., Galobardes, B., Matijasevich, A., et al. (2012) Measuring Socio-Economic Position for Epidemiological Studies in Low- and Middle-Income Countries: A Method of Measurement in Epidemiology Paper. International Journal of Epidemiology, 41, 871-886. https://doi.org/10.1093/ije/dys037

[25] Maty, S.C., Everson-Rose, S.A., Haan, M.N., et al. (2005) Education, Income, Occupation, and the 34-Year Incidence (1965-99) of Type 2 Diabetes in the Alameda County Study. International Journal of Epidemiology, 34, 1274-1281. https://doi.org/10.1093/ije/dyi167

[26] Chatterjee, S., Khunti, K. and Davies, M. (2017) Type 2 Diabetes. The Lancet, 389, 2239-2251. https://doi.org/10.1016/S0140-6736(17)30058-2 
[27] Manne-Goehler, J., Geldsetzer, P. and Agoudavi, K. (2019) Health System Performance for People with Diabetes in 28 Low- and Middle-Income Countries: A CrossSectional Study of Nationally Representative Surveys. PLoS Medicine, 16, e1002751. https://doi.org/10.1371/journal.pmed.1002751 